\title{
The association of waterpipe tobacco smoking with later initiation of cigarette smoking: a systematic review and meta-analysis exploring the gateway theory
}

\author{
Dana Al Oweini $\odot,{ }^{1}$ Mohammed Jawad $\odot,{ }^{2}$ Elie A Ak| $\left.\right|^{3,4}$
}

\begin{abstract}
- Additional material is published online only. To view please visit the journal online (http://dx.doi.org/10.1136/
\end{abstract} tobaccocontrol-2018-054870).

${ }^{1}$ Faculty of Health Sciences, American University of Beirut, Beirut, Lebanon

${ }^{2}$ Public Health Policy Evaluation Unit, Imperial College London, London, UK

${ }^{3}$ Department of Internal Medicine, American University of Beirut, Beirut, Lebanon ${ }^{4}$ Clinical Research Institute, American University of Beirut, Beirut, Lebanon

\section{Correspondence to}

Professor Elie A Akl, Department of Internal Medicine, American University of Beirut, Beirut 1107 2020, Lebanon;

ea32@aub.edu.lb

Received 2 December 2018 Revised 4 June 2019 Accepted 25 June 2019 Published Online First 30 July 2019
D Check for updates

(C) Author(s) (or their employer(s)) 2020. No commercial re-use. See rights and permissions. Published by BMJ.

To cite: Al Oweini $D$, Jawad M, AkI EA. Tob Control 2020;29:577-584.

\section{ABSTRACT}

Introduction There is a concern that waterpipe tobacco smoking (WTS) can lead to the later initiation of cigarette smoking, a concept referred to as the 'gateway theory'. The objective of the study was to systematically review the literature for the association of WTS with later initiation of cigarette smoking.

Methods We searched Medline, Embase and ISI Web of Science in April 2018 without using any language or date restrictions. We selected eligible studies, abstracted data and assessed the risk of bias using a duplicate and independent approach. We meta-analysed the ORs across eligible studies using the inverse variance method and the random-effects model. We assessed the certainty of evidence using the Grading of Recommendations Assessment, Development and Evaluation methodology. Results We included eight papers reporting on six eligible prospective cohort studies with a total of 21224 participants, belonging to the adolescent and young adult age categories. The pooled adjusted OR for the association between ever waterpipe user (compared with never waterpipe user) at baseline, with 'cigarette smoking initiation' (ever cigarette use) was $2.54(95 \% \mathrm{Cl}$ 1.60 to 4.02 ) at 6 months to 3 years follow-up (moderate certainty evidence). The pooled adjusted $O R$ for the association between ever waterpipe user (compared with never waterpipe user) at baseline, with 'current cigarette smoking' (past 30-day cigarette use) was $2.04(95 \% \mathrm{Cl}$

1.32 to 3.15 ) at $1-2$ years follow-up (moderate certainty evidence). The pooled adjusted OR for the association between past 30-day waterpipe user (compared with never waterpipe user) at baseline, with current cigarette smoking (past 30-day cigarette use) 2.46 (95\% Cl 1.73 to 3.49 ) at 6 months to 1 year follow-up (high certainty evidence).

Conclusion Our findings indicate that WTS is associated with more than doubling of the odds of later initiation of cigarette smoking, supporting the gateway theory. Strengthening WTS policies is a priority and further research is needed on the development and evaluation of appropriate clinical and public health interventions.

\section{INTRODUCTION}

Cigarette smoking is associated with high morbidity and mortality and represents a major public health burden. ${ }^{1}$ It is the leading cause for several cancerous diseases, the most common of which is lung cancer. ${ }^{2}$ It is also a major risk factor for coronary heart disease, cerebrovascular disease and chronic lung diseases. $^{3}$ It is estimated that cigarette smoking diseases lead to $>7$ million deaths worldwide yearly. ${ }^{4}$

Waterpipe tobacco smoking (WTS) has been described as a 'global epidemic'. ${ }^{5}$ WTS is highly prevalent in Eastern Mediterranean and European countries and estimates of WTS prevalence were found to be higher in youths than adults. ${ }^{6}$ For example, it is now the second most common form of smoking among young adults after cigarette smoking in the USA. ${ }^{7}$ Waterpipe smoking is harmful to health and can lead to respiratory, malignant and other types of diseases. ${ }^{8}$

There is concern that WTS can lead to the later initiation of cigarette smoking, a concept referred to as the 'gateway theory'. 9 The term gateway was first introduced in the 1980s were it was stressed that certain drugs were gateway to other more harmful drugs. ${ }^{10}$ The gateway theory insinuates evolving stages in drug use; the gateway drug model suggests that using a soft drug (eg, marijuana) acts as a precursor for the use of other drugs considered as hard or more harmful (eg, cocaine) ${ }^{10}$ Experts have hypothesised that individuals smoking waterpipe become addicted to nicotine and resort to cigarette smoking instead of WTS as a more convenient and practical source of nicotine in terms of time, space and effort. ${ }^{11}$ It is relevant to note that waterpipe smoking is often not regarded as a public health threat since both users and non-users consider it as less harmful than cigarette smoking. ${ }^{6}$ If one of the consequences of waterpipe smoking is an increased risk for cigarette smoking, the public attention to it will increase.

The objective of the study was to systematically review the literature for the association of WTS with later initiation of cigarette smoking.

\section{METHODS \\ Eligibility criteria}

We included prospective cohort studies that evaluated the association between WTS among never cigarette smokers at baseline and later initiation of cigarette smoking. We excluded studies that included patients smoking cigarettes at baseline; and studies that did not provide outcome data for WTS separately from data on other forms of tobacco use. We also excluded studies reported as abstracts for which we could not identify a full text after consultation with a medical librarian or contact with the corresponding author. 


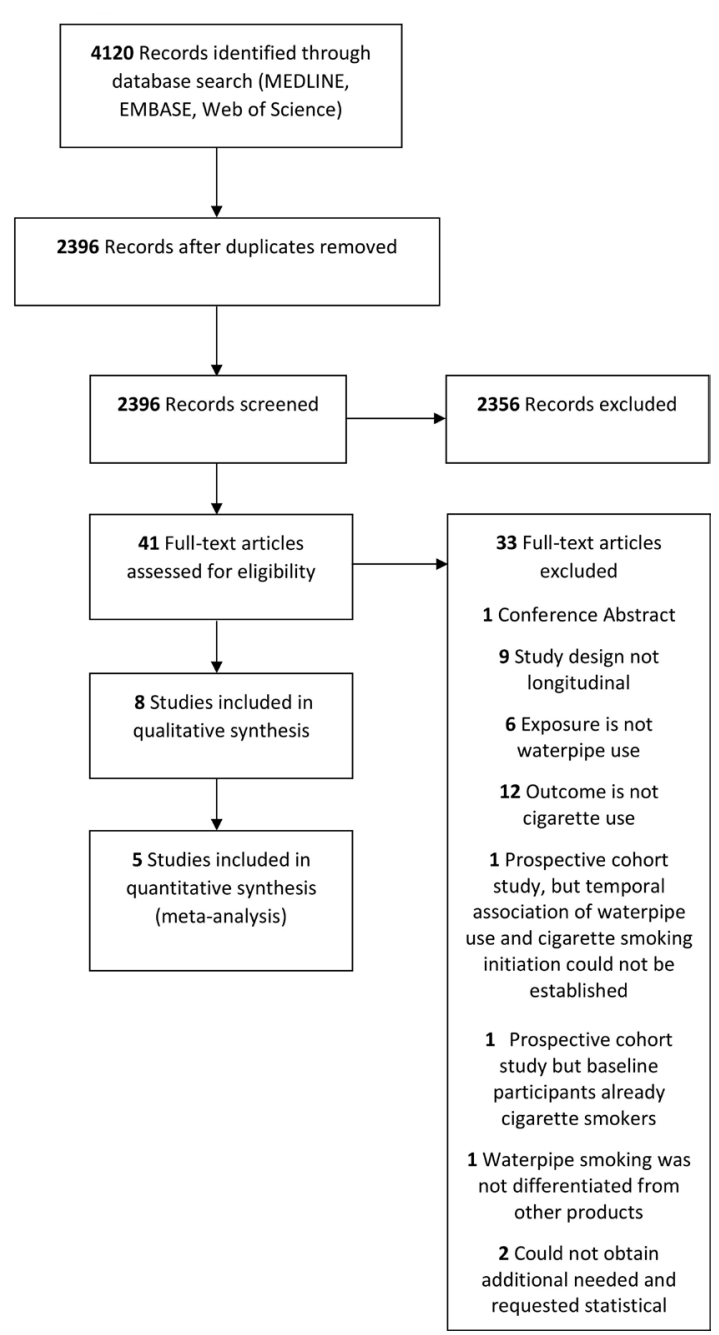

Figure 1 PRISMA flow diagram. PRISMA, Preferred Reporting Items for Systematic Reviews and Meta-Analyses.

\section{Search strategy}

We searched Medline, Embase and ISI Web of Science given evidence that these three databases provide 'adequate and enough coverage'. ${ }^{12}$ We did not search PubMed given its overlap with Medline database. We conducted the search in April 2018 without using any language or date restrictions. We designed the search strategy with the help of a medical librarian experienced in systematic reviews. The strategy included terms for 'waterpipe' and its synonyms using spelling variations (eg, 'hookah', 'shisha', 'narghile') and other culturally specific terms. It also included terms for 'cigarette smoking' and its synonyms using spelling variations (online supplementary table S1). We also searched the reference lists of included studies.

\section{Selection process}

Two reviewers (DA and MJ) screened in duplicate and independently the titles and abstracts of identified citations to assess them for potential eligibility. We retrieved the full texts of citations judged as potentially eligible by at least one reviewer. Then we screened, in duplicate, and independently the full texts using a standardised and pilot-tested screening form. The reviewers resolved disagreements by discussion, and when needed, with the help of a third reviewer (EAA). We requested additional data from the corresponding authors of studies when needed (eg, data on inclusion of individuals who are cigarette smokers at baseline).

\section{Data abstraction}

The two reviewers (DA and MJ) abstracted data from included studies in duplicate, and independently using a standardised and pilot-tested abstraction form. They resolved disagreements by discussion, and when needed, with the help of a third reviewer (EAA).

We abstracted the following data from included studies: study design, eligibility criteria, characteristics of participants (eg, age, sex, number), exposure, outcomes assessed, results (noting whether they reported ORs or relative risks), and governance which included the funding source and reported conflicts of interest.

We attempted to contact the authors of studies that were potentially eligible but did not report the data needed for our analyses. We emailed those authors asking for the analyses that were restricted to cigarette smoking only and not combined with other forms of tobacco smoking (eg, cigars).$^{13}$

\section{Risk of bias assessment}

The two reviewers (DA and $\mathrm{MJ}$ ) assessed the quality of included studies in duplicate, and independently. They resolved disagreements by discussion, and when needed, with the help of a third reviewer (EAA). We assessed the following risk of bias criteria for observational studies suggested by the Grading of Recommendations Assessment, Development and Evaluation (GRADE) working group ${ }^{14}$ : developing and applying appropriate eligibility criteria, measurement of the exposure, measurement of the outcome, controlling for confounding and completeness of data.

\section{Data analysis}

When a study reported more than one relevant effect estimate, we selected the one that adjusted for the maximum number of confounders, particularly for other forms of tobacco smoking. We took the natural logarithm of reported ORs (ln (ORs)) and SEs and pooled them across eligible studies using the inverse variance method and the random-effects model. We measured heterogeneity across studies using the $\mathrm{I}^{2}$ statistic. We considered heterogeneity to be high when $\mathrm{I}^{2}$ was $>50 \%$. We used Review Manager software V.5.3 for all analyses. We assessed the certainty of evidence using the GRADE guidance developed for evidence about prognosis. ${ }^{15}$

\section{RESULTS}

\section{Selection process}

Figure 1 shows the Preferred Reporting Items for Systematic Reviews and Meta-Analyses flow diagram. Out of the 4120 citations, 2396 records remained after the removal of duplicates and 41 full text articles were assessed for eligibility after excluding the non-relevant citations. Out of the 41 citations, 8 papers reported on 6 studies that met the eligibility criteria. These six studies included a total of 21224 participants, belonging to the adolescent and young adult age categories. We excluded 33 studies for reasons mentioned in online supplementary table S2. Two studies could not be included due to the inability to obtain all needed statistical information. ${ }^{131617}$

\section{Characteristics of included studies}

Table 1 shows the characteristics of the six eligible studies, all of which were prospective cohort studies. Four studies were from the USA, one from Jordan and one from the Netherlands. The 


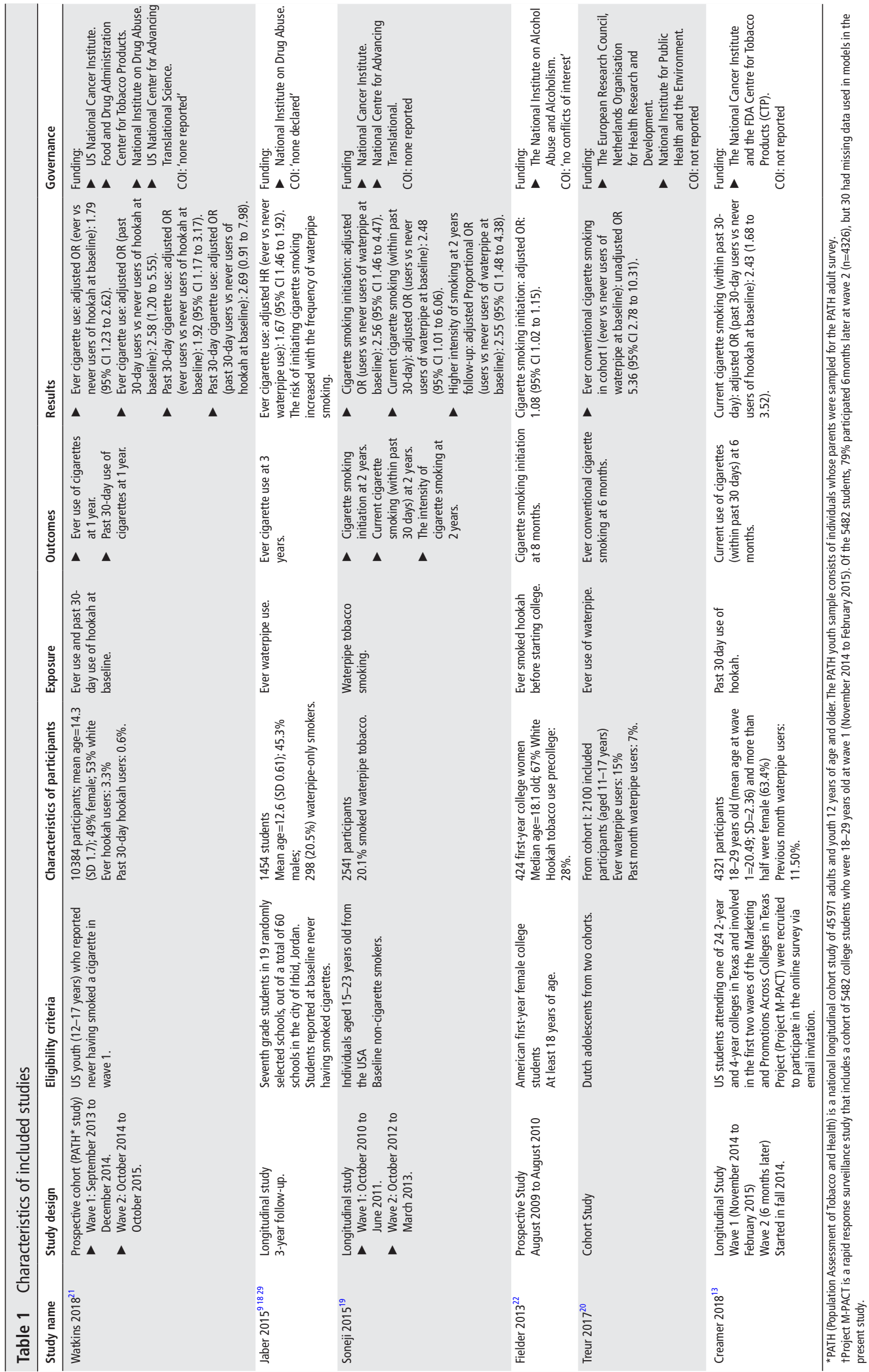


Table 2 Risk of bias of included studies

\begin{tabular}{|c|c|c|c|c|c|}
\hline \multirow[b]{2}{*}{ Study name } & \multirow{2}{*}{$\begin{array}{l}\text { Developing and applying } \\
\text { appropriate eligibility criteria } \\
\text { High, low, unclear }\end{array}$} & \multirow{2}{*}{$\begin{array}{l}\text { Measurement of exposure } \\
\text { High, low, unclear }\end{array}$} & \multirow{2}{*}{$\begin{array}{l}\text { Measurement of outcome } \\
\text { High, low, unclear }\end{array}$} & \multirow{2}{*}{$\begin{array}{l}\text { Controlling for confounding } \\
\text { High, low, unclear }\end{array}$} & \multirow{2}{*}{$\begin{array}{l}\text { Completeness of data } \\
\text { High, low, unclear }\end{array}$} \\
\hline & & & & & \\
\hline Watkins $2018^{21}$ & $\begin{array}{l}\text { Low } \\
\text { 'The PATH youth sample consists } \\
\text { of individuals whose parents } \\
\text { were sampled for the PATH adult } \\
\text { survey' } \\
\text { Selection of exposed and } \\
\text { unexposed from same } \\
\text { population. }\end{array}$ & $\begin{array}{l}\text { Low } \\
\text { 'The PATH Study adapted many } \\
\text { items from well-established existing } \\
\text { national surveys'. } \\
\text { 'Nicotine dependence items in } \\
\text { the PATH Study's questionnaires } \\
\text { were based in part on the National } \\
\text { Epidemiological Survey on Alcohol } \\
\text { and Related Conditions Survey'. } \\
\text { 'Other health-related items in } \\
\text { the PATH Study questionnaires } \\
\text { came from validated screeners } \\
\text { including the Global Appraisal of } \\
\text { Individual Needs (GAIN) and Patient } \\
\text { Reported Outcomes Measurement } \\
\text { Information System (PROMIS)'. } \\
\text { 'The PATH Study questionnaires also } \\
\text { included items from international, } \\
\text { state and privately funded tobacco } \\
\text { surveillance surveys, such as the ITC } \\
\text { Project, the Visual Media Influences } \\
\text { on Adolescent and Young Adult } \\
\text { Smoking Behaviour surveys and the } \\
\text { Minnesota Adult Tobacco Survey'. } \\
30\end{array}$ & $\begin{array}{l}\text { Low } \\
\text { 'The PATH Study adapted many } \\
\text { items from well-established } \\
\text { existing national surveys'. } \\
\text { 'Nicotine dependence items in } \\
\text { the PATH Study's questionnaires } \\
\text { were based in part on the National } \\
\text { Epidemiological Survey on Alcohol } \\
\text { and Related Conditions Survey'. } \\
\text { 'Other health-related items in the } \\
\text { PATH Study questionnaires came } \\
\text { from validated screeners including } \\
\text { the Global Appraisal of Individual } \\
\text { Needs (GAIN) and Patient } \\
\text { Reported Outcomes Measurement } \\
\text { Information System (PROMIS)'. } \\
\text { 'The PATH Study questionnaires } \\
\text { also included items from } \\
\text { international, state and privately } \\
\text { funded tobacco surveillance } \\
\text { surveys, such as the ITC Project, } \\
\text { the Visual Media Influences on } \\
\text { Adolescent and Young Adult } \\
\text { Smoking Behaviour surveys and } \\
\text { the Minnesota Adult Tobacco } \\
\text { Survey'. } \\
30\end{array}$ & $\begin{array}{l}\text { Low } \\
\text { 'To account for variation in smoking } \\
\text { across sociodemographic groups: } \\
\text { adjusted for sex, age, race/ethnicity } \\
\text { (black or African American, Latino } \\
\text { or other), parental educational level } \\
\text { (bachelor's degree or higher) and } \\
\text { urban residence' }\end{array}$ & $\begin{array}{l}\text { Low } \\
\text { 'Of } 13651 \text { wave } 1 \text { youth } \\
\text { participants, } 11996 \text { completed } \\
\text { wave } 2 \text { (unweighted retention, } \\
87.9 \% \text { ), including } 1915 \text { individuals } \\
\text { who reached } 18 \text { years of age before } \\
\text { follow-up and were administered } \\
\text { the wave } 2 \text { adult survey'. } \\
\text { Table } 2 \text { within }{ }^{21} \text { : } \\
\text { For cigarette use ever, ... the largest } \\
\text { fraction of missing information } \\
\text { was } 0.011 \text { in model } 1 \text { and } 0.0186 \\
\text { in model } 2 \\
\text { For past } 30 \text { day cigarette use, ... } \\
\text { and the largest fraction of missing } \\
\text { information was } 0.028 \text { in model } 1 \\
\text { and } 0.032 \text { in model } 2 \\
\text { Table } 3 \text { within }{ }^{21} \text { : } \\
\text { For cigarette use ever, ... the largest } \\
\text { fraction of missing information } \\
\text { was } 0.009 \text { in model } 1 \text { and } 0.021 \text { in } \\
\text { model } 2 . \\
\text { For past } 30 \text { day cigarette use, ... } \\
\text { the largest fraction of missing } \\
\text { information was } 0.018 \text { in model } 1 \\
\text { and } 0.033 \text { in model } 2 \text { '. }\end{array}$ \\
\hline Jaber $2015^{91829}$ & $\begin{array}{l}\text { Low } \\
\text { ' } 60 \text { Irbid schools were stratified } \\
\text { by sex (boys, girls, and mixed } \\
\text { sex schools) and type (public } \\
\text { and private). A random sample } \\
\text { of } 19 \text { schools was selected } \\
\text { with probability proportionate } \\
\text { to size'. }\end{array}$ & $\begin{array}{l}\text { Low } \\
\text { 'Smoking behaviour was assessed } \\
\text { using a pilot-tested questionnaire } \\
\text { developed in accordance with WHO } \\
\text { international guidelines, and several } \\
\text { instruments validated in Arabic, } \\
\text { such as the GYTS'. } \\
\text { 'To ensure the validity of the } \\
\text { responses, parents or school } \\
\text { personnel were not allowed to } \\
\text { attend the data collection session'. }\end{array}$ & $\begin{array}{l}\text { Low } \\
\text { 'Smoking behaviour was assessed } \\
\text { using a pilot-tested questionnaire } \\
\text { developed in accordance with } \\
\text { WHO international guidelines, and } \\
\text { several instruments validated in } \\
\text { Arabic, such as the GYTS'. } \\
\text { 'To ensure the validity of the } \\
\text { responses, parents or school } \\
\text { personnel were not allowed to } \\
\text { attend the data collection session'. }\end{array}$ & $\begin{array}{l}\text { Low } \\
\text { 'Modelling included: sex; age; pocket } \\
\text { money; educational level of parents; } \\
\text { whether parents, siblings, friends, } \\
\text { teacher smoked cigarettes; relation } \\
\text { with parents, siblings, teachers and } \\
\text { classmates; intention to smoke; } \\
\text { refusal of self-efficacy; beliefs } \\
\text { (cigarette smoker has more friends, } \\
\text { cigarette smoking is more attractive, } \\
\text { cigarette smoking reduces weight, } \\
\text { cigarette smoking harms health, easy } \\
\text { to quit cigarette after smoking a } \\
\text { year); intention to smoke next year; } \\
\text { and whether the student has seen } \\
\text { advertisements promoting or warning } \\
\text { against cigarette smoking or actor } \\
\text { smoking in the media, and warning } \\
\text { label on cigarette packs'. }\end{array}$ & $\begin{array}{l}\text { Low } \\
\text { Censored in interval: } \\
\quad \text { Baseline to year } 1 \text { (grade 7): } \\
6.9 \% \text {. } \\
\quad \text { Year } 1 \text { to year } 2 \text { (grade 8): } \\
\quad 0.7 \% . \\
\quad \text { Year } 2 \text { to year } 3 \text { (grade 9): } \\
8.4 \% .\end{array}$ \\
\hline Soneji $2015^{19}$ & $\begin{array}{l}\text { Low } \\
\text { 'Our data come from the first } 2 \\
\text { waves of the Dartmouth Media, } \\
\text { Advertising, and Health Study'. } \\
\text { 'At baseline } 3342 \text { individuals } \\
15-23 \text { years old were recruited } \\
\text { from } 6466 \text { eligible households } \\
\text { via a random digit- dialling } \\
\text { telephone survey using landline } \\
(67.0 \%) \text { and cell phone frames } \\
(33.0 \%) \text {. Of } 3342 \text { respondents, } \\
2541 \text { also completed a web- } \\
\text { based visual survey at baseline. } \\
\text { In wave } 2 \text { of the study we } \\
\text { followed up } 2541 \text { respondents } \\
\text { who had completed both } \\
\text { portions of the base- line survey; } \\
1596 \text { completed the web-based } \\
\text { visual survey at wave 2'. }\end{array}$ & $\begin{array}{l}\text { Unclear } \\
\text { No relevant information reported } \\
\text { by authors. }\end{array}$ & $\begin{array}{l}\text { Unclear } \\
\text { No relevant information reported } \\
\text { by authors. }\end{array}$ & $\begin{array}{l}\text { Low } \\
\text { 'Covariates: we assessed Demographic } \\
\text { characteristics of respondents: their } \\
\text { age, sex, race/ethnicity, region, } \\
\text { urbanicity'. } \\
\text { Socioeconomic status: maternal } \\
\text { educational level, annual parental } \\
\text { household income } \\
\text { Behavioural risk factors: whether any } \\
\text { of the respondents' friends smoked } \\
\text { cigarettes, their parental cigarette } \\
\text { smoking status } \\
\text { 'to address the possibility that the } \\
\text { results were driven by a subset of } \\
\text { deviant-prone adolescents and young } \\
\text { adults, we controlled for another risky } \\
\text { behaviour, namely, problem drinking } \\
\text { ( } \geq 6 \text { drinks per occasion): considered } \\
\text { binge drinking'. }\end{array}$ & $\begin{array}{l}\text { Low } \\
\text { 'We performed multiple imputation } \\
\text { to address missing data for } \\
\text { maternal educational level ( } 4.2 \% \\
\text { missing) and annual parental } \\
\text { household income }(29.5 \% \text { missing)'. } \\
\text { 'Our multiple imputation method } \\
\text { assumed that these data were } \\
\text { missing at random'. }\end{array}$ \\
\hline Fielder $2013^{22}$ & $\begin{array}{l}\text { Unclear } \\
\text { 'Interested women signed up } \\
\text { on a website, were screened to } \\
\text { ensure eligibility'. } \\
\text { This might indicate a risk of } \\
\text { selection bias. } \\
\text { 'Eligible participants were first- } \\
\text { year female college students } \\
\text { ( } \mathrm{N}=483 \text { ) engaged in a } 13 \text { month } \\
\text { longitudinal study from August } \\
2009 \text { to August } 2010 \text { designed } \\
\text { to investigate health behaviours } \\
\text { and relationships during the } \\
\text { transition to college'. }\end{array}$ & $\begin{array}{l}\text { Unclear } \\
\text { No relevant information reported } \\
\text { by authors. }\end{array}$ & $\begin{array}{l}\text { Unclear } \\
\text { No relevant information reported } \\
\text { by authors. }\end{array}$ & $\begin{array}{l}\text { Low } \\
\text { 'We tested demographics as potential } \\
\text { covariates of hookah, cigarette, and } \\
\text { marijuana initiation using logistic } \\
\text { regression'. }\end{array}$ & $\begin{array}{l}\text { Low } \\
\text { 'There were no differences between } \\
\text { included participants and women } \\
\text { excluded due to missing data } \\
\text { ( } n=59 \text { ) on age, race, ethnicity, } \\
\text { impulsivity, sensation-seeking, or } \\
\text { frequency of pre-college hookah, } \\
\text { cigarette, mari- juana use, or binge } \\
\text { drinking (all ps }>0.05) \text { '. }\end{array}$ \\
\hline
\end{tabular}




\begin{tabular}{|c|c|c|c|c|c|}
\hline \multirow[b]{2}{*}{ Study name } & $\begin{array}{l}\text { Developing and applying } \\
\text { appropriate eligibility criteria }\end{array}$ & Measurement of exposure & Measurement of outcome & Controlling for confounding & Completeness of data \\
\hline & High, low, unclear & High, low, unclear & High, low, unclear & High, low, unclear & High, low, unclear \\
\hline Treur $2017^{20}$ & $\begin{array}{l}\text { Low } \\
\text { 'Cohort I consists of } 6819 \\
\text { adolescents aged } 11-17 \text { years } \\
\text { (mean age=13.8 (SD=1.1), } \\
48.2 \% \text { female) who were } \\
\text { enrolled in a study that } \\
\text { investigated the impact of } \\
\text { school smoking policy on } \\
\text { changes in adolescents' } \\
\text { smoking behaviour. Data were } \\
\text { collected in 2014-2015 from } \\
19 \text { secondary schools randomly } \\
\text { selected across the Netherlands'. }\end{array}$ & $\begin{array}{l}\text { Unclear } \\
\text { No relevant information reported } \\
\text { by authors. }\end{array}$ & $\begin{array}{l}\text { Unclear } \\
\text { No relevant information reported } \\
\text { by authors. }\end{array}$ & $\begin{array}{l}\text { Low } \\
\text { 'Besides age, sex and educational } \\
\text { attainment, a composite score of } \\
\text { smoking propensity at T0 was added } \\
\text { as covariate as well as an interaction } \\
\text { term between propensity to smoke } \\
\text { and ever use of e-cigarettes with } \\
\text { nicotine/e-cigarettes without nicotine/ } \\
\text { waterpipe'. }\end{array}$ & $\begin{array}{l}\text { Unclear } \\
\text { Loss to follow-up not reported. }\end{array}$ \\
\hline Creamer $2018^{13}$ & $\begin{array}{l}\text { Low } \\
\text { 'Students attending one of } 24 \\
\text { 2-year and 4-year colleges in } \\
\text { Texas and involved in the first } \\
\text { two waves of the Marketing and } \\
\text { Promotions Across Colleges in } \\
\text { Texas Project (Project M-PACT) } \\
\text { were recruited to participate } \\
\text { in the online survey via email } \\
\text { invitation'. }\end{array}$ & $\begin{array}{l}\text { Low } \\
\text { 'Measures for the current study } \\
\text { were modelled after existing } \\
\text { surveys and were initially reviewed } \\
\text { by nine tobacco control experts } \\
\text { who provided guidance on } \\
\text { revisions. Final item modifications } \\
\text { were conducted through an } \\
\text { iterative process of cognitive } \\
\text { interviewing with young adults who } \\
\text { were not part of the present study'. }\end{array}$ & $\begin{array}{l}\text { Low } \\
\text { 'Measures for the current study } \\
\text { were modelled after existing } \\
\text { surveys and were initially reviewed } \\
\text { by nine tobacco control experts } \\
\text { who provided guidance on } \\
\text { revisions. Final item modifications } \\
\text { were conducted through an } \\
\text { iterative process of cognitive } \\
\text { interviewing with young adults } \\
\text { who were not part of the present } \\
\text { study'. }\end{array}$ & $\begin{array}{l}\text { Low } \\
\text { 'Sex, age, race/ethnicity, type of } \\
\text { college and parental education were } \\
\text { included as covariates'. }\end{array}$ & $\begin{array}{l}\text { Low } \\
\text { 'Attrition analyses were conducted } \\
\text { to determine if students who were } \\
\text { eligible to participate at wave } \\
\text { two but did not participate were } \\
\text { significantly different from those } \\
\text { who did participate. Because } \\
\text { missing data were related to } \\
\text { observed variables, it was assumed } \\
\text { that the data were missing at } \\
\text { random'. }\end{array}$ \\
\hline
\end{tabular}

age of participants ranged across studies between 11 and 29 years old. The studies collected data between the years 2009 and 2015. The percentage of ever waterpipe users at baseline ranged across studies from $3.3 \%$ and $28.0 \%$ while the percentage of past 30-day waterpipe users ranged across studies from $0.6 \%$ and $11.50 \%$. Five studies assessed cigarette smoking initiation (ever cigarette use) as the outcome, while three studies assessed current (past 30-day) cigarette smoking as the outcome. The follow-up time of outcome assessment ranged between 6 months and 3 years.

The funding of these studies mainly came from governmental organisations. Two studies did not report on the COI of authors, while the remaining four studies reported the absence of any COIs. As a result, the findings increased the trustworthiness of the included studies.

Table 2 reports the detailed risk of bias assessments for all included studies, while figure 2 summarises those assessments. Five out of the six studies applied appropriate eligibility criteria where randomisation was applied and the selection of the exposed and the unexposed were from the same population. ${ }^{1318-21}$ The sixth study relied on the interest of the individuals as a way for the recruitment of participants, which might indicate a risk of selection bias. ${ }^{22}$ Three studies, Creamer et al ${ }^{13}$, Watkins et $a l^{21}$ and Jaber et $a l^{18}$ used validated tools for the measurement of the exposure and outcome, however none of the remaining three studies provided clear information on the validity of those tools. All of the included studies adjusted and controlled for sociodemographic, and behavioural risk factors that could be associated with waterpipe and cigarette smoking. We were not able to formally assess the risk of publication bias given the relatively small number of included studies. It is more likely that publication bias affects studies showing no association as opposed to studies showing a positive association. If that is the case, publication bias would have overestimated the association between WTS and later initiation of cigarette smoking.
Five studies assessed the association between ever waterpipe use (compared with never waterpipe use) at baseline, with cigarette smoking initiation (ever cigarette use) at 6 months to 3 years follow-up. One of those studies analysed waterpipe use as a continuous variable, so we could not include it in the meta-analysis. It found an adjusted OR of 1.08 (95\% CI 1.02 to 1.15$)$, that is, each extra 'time they ever smoked waterpipe before starting college' was associated with 0.08 increase in the odds of initiating cigarette use. The pooled adjusted OR for the remaining four of those studies was 2.54 (95\% CI 1.60 to 4.02 ); $\mathrm{I}^{2}=76 \%$ (figure 3 ). We assessed the certainty of evidence as moderate as there were concerns about risk of bias in two of the included studies. We judged inconsistency as not serious in

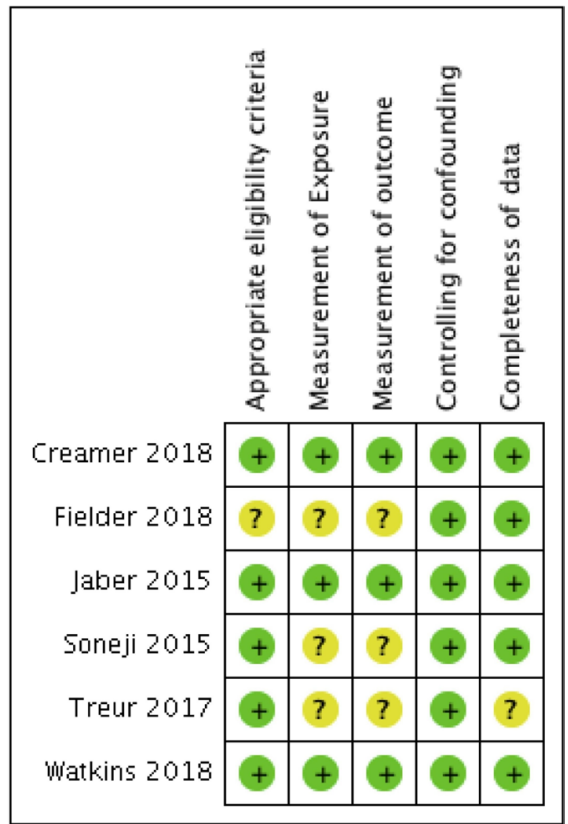

Figure 2 Risk of Bias of included studies 


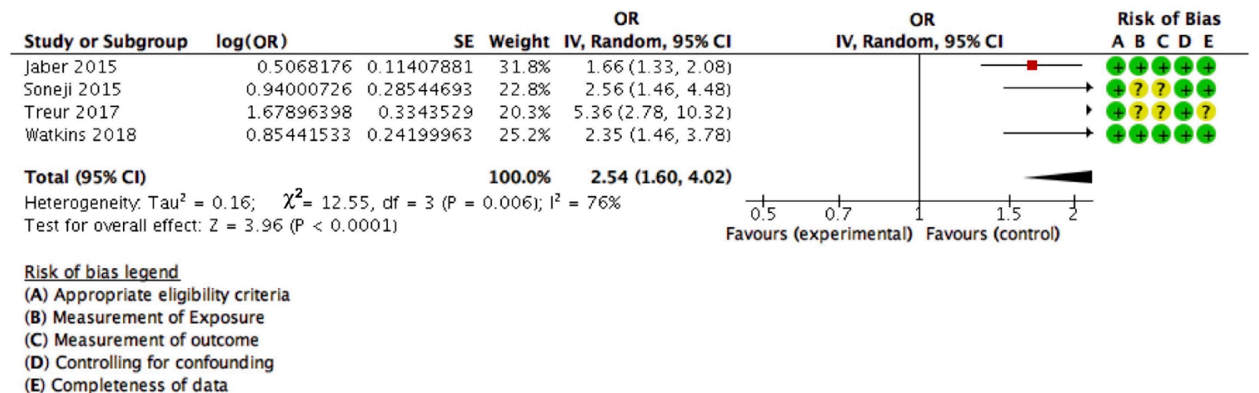

Figure 3 Pooled analysis for the association between exposure to waterpipe tobacco smoking and ever use of cigarette.

spite of the high statistical heterogeneity $\left(\mathrm{I}^{2}=76 \%\right)$ because all ORs indicated a positively strong association.

One study assessed the association between current waterpipe use (compared with never waterpipe use) at baseline, with 'cigarette smoking initiation' at 1 year follow-up. ${ }^{21}$ The reported adjusted OR was 2.58 (95\% CI 1.20 to 5.55 ).

Current cigarette use:

Two studies assessed the association between ever waterpipe use (compared with never waterpipe use) at baseline, with 'current cigarette smoking' (past 30-day cigarette use) at 1-2 years follow-up. The pooled adjusted OR was 2.04 (95\% CI 1.32 to 3.15 ); $\mathrm{I}^{2}=0 \%$ (figure 4 ). We assessed the certainty of evidence as moderate as there were concerns about risk of bias in one of the included studies.

Two studies assessed the association between current waterpipe users (compared with never waterpipe users) at baseline, with current cigarette smoking at 6 months to 1 year follow-up. The pooled adjusted OR was 2.46 (95\% CI 1.73 to 3.49 ) (figure 5). We assessed the certainty of evidence as high as there were no concerns about risk of bias, indirectness, imprecision, inconsistency or publication bias.

\section{DISCUSSION}

We identified six longitudinal studies assessing the association of WTS with later initiation of cigarette smoking. The meta-analysis of these studies indicated that WTS is associated with more than doubling of the odds of later initiation of cigarette smoking. We rated the risk of bias in the included studies as unclear to low.

Our findings support the gateway theory that suggests evolving stages in using harmful substances. The original gateway drug model proposes that using a soft drug (eg, marijuana) increases the likelihood of later experimenting with hard drugs (eg, cocaine). ${ }^{10}$ In the context of tobacco smoking, there is consistent evidence that waterpipe is perceived as less harmful (ie, softer) than cigarette smoking. ${ }^{23}$ The findings of this meta-analysis suggest that initial exposure to waterpipe in the youth period increases the likelihood of switching later to cigarette smoking. However, one has to consider that waterpipe smoking is not a 'soft' exposure, as it can lead to respiratory, malignant and other types of diseases. ${ }^{8}$

There is evidence suggesting that the gateway theory applies to other tobacco products such as e-cigarettes. A systematic review by Soneji et al $^{24}$ found that e-cigarette smoking leads to subsequent initiation of cigarette smoking. ${ }^{24}$ One cohort study provided evidence for the association of snus use with later initiation of cigarette smoking. ${ }^{19}$

This study has a number of strengths. First, we followed the standard methods of conducting and reporting systematic reviews. $^{25} 26$ Second, we restricted eligibility to prospective cohort studies in which waterpipe smoking preceded cigarette smoking initiation. This temporal relationship makes us more confident that the observed association is causal, in support of the gateway theory. Third, the results of included studies were relatively consistent, which further increases the certainty in the evidence supporting the gateway theory. Fourth, the included studies adjusted for possible confounding variables (eg, sociodemographic and behavioural) further increasing our confidence in the findings. In spite of that, residual confounding (eg, related to susceptibility to cigarette smoking) and risk of publication bias remain possible.

One limitation of this review is that we could not include all studies in the meta-analysis. Still, we reported the statistical data of one of those studies along with the pooled data. ${ }^{22} \mathrm{We}$ had to exclude two other studies that could have contributed to the analysis since additional needed and requested statistical information could not be obtained. ${ }^{131617}$ Second, it would have been interesting to conduct a stratified analysis by age group to detect any age-related subgroup effect, given the differences in patterns of waterpipe and cigarette smoking respectively. However, we could not conduct such analysis due to the low number of eligible studies (ie, three studies included adolescents, two studies included young adults and one study included both; no study included older adults). Third, and due to the low number of included studies, we were not able to assess the risk of publication bias. Fourth, the included studies did not asses the proportion of waterpipe users that became regular smokers;

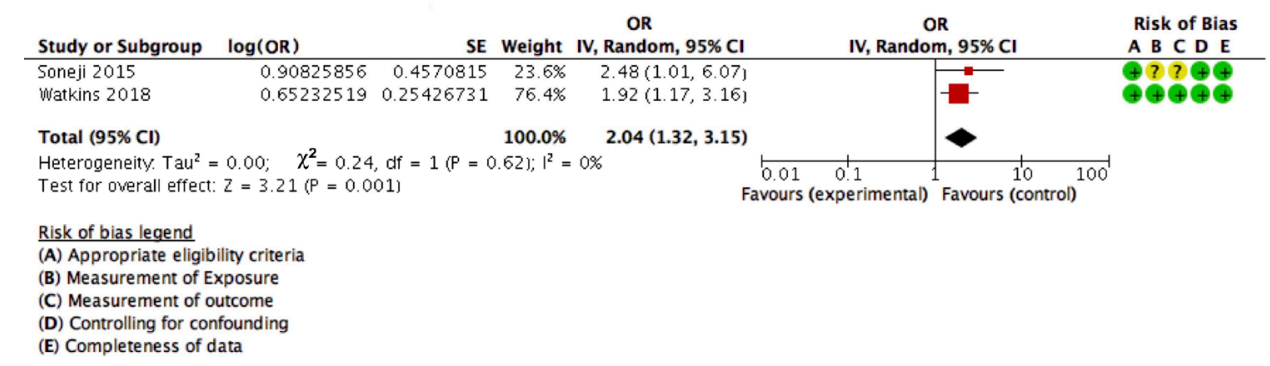

Figure 4 Pooled analysis for the association between exposure to waterpipe tobacco smoking and past 30-day use of cigarette. 


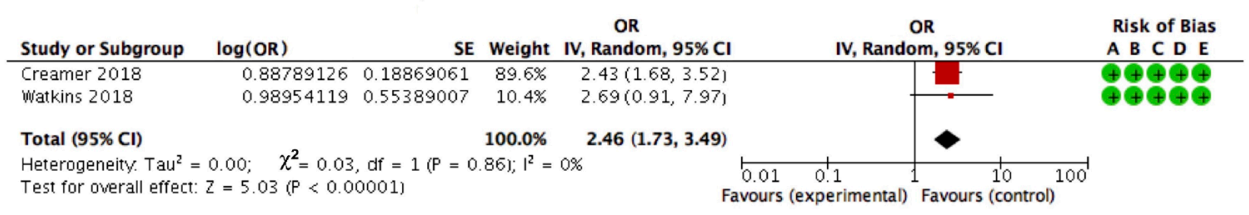

Risk of bias legend

(A) Appropriate eligibility criteria

(A) Approprlate eligibility criteria

(B) Measurement of Exposure

(D) Controlling for confounding

(D) Controlling for confoundin

Figure 5 Pooled analysis for the association between past 30-day exposure to waterpipe tobacco smoking and past 30-day use of cigarette.

however, the effect of waterpipe use on regular cigarette smoking should be correlated with our findings where most of the studies assessed past 30-day use. Finally, although we searched three comprehensive databases, there is a possibility that some articles might have been missed.

Based on the findings of our systematic review and considering that cigarette smoking is a major public health burden, there is a need for both clinical and public health interventions to help in both preventing the initiation and quitting of waterpipe use. $^{27}$ Potential approaches include higher taxation and stricter regulations on waterpipe smoking among the youths and adolescents. In addition to regulatory restrictions on the advertising campaigns and stricter limits on the promotion of waterpipe tobacco flavours. Awareness campaigns are also needed to shed the light on the severity of this association of waterpipe smoking with later initiation of cigarette smoking especially among youth, and on the harmful effects of both waterpipe and cigarette smoking. Also, adding health warning labels on the waterpipe device were found to be effective in encouraging quitting attempts and discouraging experimenting with WTS, ${ }^{28}$ thus policies are needed to enforce this action.

On the other hand, there is a need for further research on the development and evaluation of interventions as well as awareness campaigns to help with preventing the initiation and quitting of waterpipe use. In addition, there is a need for more research in the Middle East and Europe given the high public burden in those areas. Also, future research could explore the predictors of initiation of cigarette smoking among waterpipe users, for example, the nicotine concentration from waterpipe smoking, and susceptibility to cigarette smoking.

\section{What this paper adds}

What is already known on this subject

- The prevalence of waterpipe tobacco smoking (WTS) is on the rise globally.

- There is a concern that WTS can lead to the later initiation of cigarette smoking, a concept referred to as the 'gateway theory'.

What important gaps in knowledge exist on this topic

- While a number of studies exploring the gateway theory have been published, there no systematic synthesis of that evidence exists

What this study adds

- WTS is associated with more than doubling of the odd of the later initiation of cigarette smoking, which supports the gateway theory.

\section{CONCLUSION}

We systematically reviewed the literature for the association of WTS with later initiation of cigarette smoking. We used data from six cohort studies that included 21224 participants overall. The meta-analysis found that WTS is associated with more than double of the odds of subsequent initiation of cigarette smoking. The findings highlight the importance of strengthening the WTS policies. In addition, further research is needed for the development and evaluation of interventions to prevent the initiation and aid in the quitting of waterpipe use.

Acknowledgements We thank Dr. Alexandra Loukas and Dr. MeLisa Creamer for their assistance with providing us with requested statistical data analyses.

Contributors EA and DA contributed to the study conception and design. DA developed the search strategy. DA and MJ contributed to the screening of articles and the acquisition of the data from the selected studies. Together DA, MJ, and EA contributed to the analysis and interpretation of data. DA and EA drafted the manuscript. DA, MJ, EA contributed to the critical revision and the final version of the manuscript. EA, the corresponding author attests that all listed authors meet authorship criteria and that no others meeting the criteria have been omitted.

Funding The authors have not declared a specific grant for this research from any funding agency in the public, commercial or not-for-profit sectors.

Competing interests None declared.

Patient consent for publication Not required.

Provenance and peer review Not commissioned; externally peer reviewed.

\section{ORCID iDs}

Dana Al Oweini http://orcid.org/0000-0003-1552-9321

Mohammed Jawad http://orcid.org/0000-0002-1051-2136

\section{REFERENCES}

1 Reitsma MB, Fullman N, Ng M, et al. Smoking prevalence and attributable disease burden in 195 countries and territories, 1990-2015: a systematic analysis from the global burden of disease study 2015. The Lancet 2017:389:1885-906.

2 Lortet-Tieulent J, Kulhánová I, Jacobs EJ, et al. Cigarette smoking-attributable burden of cancer by race and ethnicity in the United States. Cancer Causes \& Control 2017;28:981-4.

3 Saha SP, Bhalla DK, Whayne TF, et al. Cigarette smoke and adverse health effects: an overview of research trends and future needs. Int J Angiol 2007;16:77-83.

4 WHO. Who report on the global tobacco epidemic 2017: World Health organization, 2017. Available: http://www.who.int/tobacco/global_report/2017/en/

5 Maziak W. The global epidemic of waterpipe smoking. Addict Behav 2011;36:1-5.

6 Jawad M, Charide R, Waziry R, et al. The prevalence and trends of waterpipe tobacco smoking: a systematic review. PLoS One 2018;13:e0192191.

7 Cobb C, Ward KD, Maziak W, et al. Waterpipe tobacco smoking: an emerging health crisis in the United States. Am J Health Behav 2010;34:275-85.

8 Waziry R, Jawad M, Ballout RA, et al. The effects of waterpipe tobacco smoking on health outcomes: an updated systematic review and meta-analysis. Int J Epidemiol 2017;46:32-43.

9 Mzayek F, Khader Y, Eissenberg T, et al. Patterns of water-pipe and cigarette smoking initiation in schoolchildren: Irbid longitudinal smoking study. Nicotine Tob Res 2012;14:448-54.

10 Kandel DB. Stages and pathways of drug involvement examining the gateway hypothesis. The Pitt building, Trumpington Street, Cambridge, United Kingdom: The press SYNDICATE of the University of Cambridge, 2002. 
11 McKelvey KL, Wilcox ML, Madhivanan P, et al. Time trends of cigarette and waterpipe smoking among a cohort of school children in Irbid, Jordan, 2008-11. Eur J Public Health 2013;23:862-7.

12 Bramer WM, Rethlefsen ML, Kleijnen J, et al. Optimal database combinations for literature searches in systematic reviews: a prospective exploratory study. Syst Rev 2017;6:245.

13 Creamer MR, Loukas A, Clendennen S, et al. Longitudinal predictors of cigarette use among students from 24 Texas colleges. J Am Coll Health 2018:617-24.

14 Guyatt GH, Oxman AD, Vist G, et al. GRADE guidelines: 4. Rating the quality of evidence--study limitations (risk of bias). J Clin Epidemiol 2011;64:407-15.

15 Iorio A, Spencer FA, Falavigna M, et al. Use of grade for assessment of evidence about prognosis: rating confidence in estimates of event rates in broad categories of patients. BMJ 2015;350.

16 Pénzes M, Foley KL, Nădășan V, et al. Bidirectional associations of e-cigarette, conventional cigarette and waterpipe experimentation among adolescents: a crosslagged model. Addict Behav 2018;80:59-64.

17 Case KR, Creamer MR, Cooper MR, et al. Hookah use as a predictor of other tobacco product use: a longitudinal analysis of Texas college students. Addict Behav 2018;87:131-7.

18 Jaber R, Madhivanan P, Veledar E, et al. Waterpipe a gateway to cigarette smoking initiation among adolescents in Irbid, Jordan: a longitudinal study. Int J Tuberc Lung Dis 2015;19:481-7.

19 Soneji S, Sargent JD, Tanski SE, et al. Associations between initial water pipe tobacco smoking and snus use and subsequent cigarette smoking: results from a longitudinal study of US adolescents and young adults. JAMA Pediatr 2015;169:129-36.

20 Treur JL, Rozema AD, Mathijssen JJP, et al. E-Cigarette and waterpipe use in two adolescent cohorts: cross-sectional and longitudinal associations with conventional cigarette smoking. Eur J Epidemiol 2018;33:323-34.
21 Watkins SL, Glantz SA, Chaffee BW. Association of Noncigarette tobacco product use with future cigarette smoking among youth in the population assessment of tobacco and health (path) study, 2013-2015. JAMA Pediatr 2018;172:181.

22 Fielder RL, Carey KB, Carey MP. Hookah, cigarette, and marijuana use: a prospective study of smoking behaviors among first-year College women. Addict Behav 2013;38:2729-35.

23 AkI EA, Ward KD, Bteddini D, et al. The allure of the waterpipe: a narrative review of factors affecting the epidemic rise in waterpipe smoking among young persons globally. Tob Control 2015;24(Suppl 1):i13-21.

24 Soneji S, Barrington-Trimis JL, Wills TA, et al. Association between initial use of ecigarettes and subsequent cigarette smoking among adolescents and young adults: a systematic review and meta-analysis. JAMA pediatrics 2017;171:788-97.

25 Higgins JPT, Green S. Cochrane Handbook for systematic reviews of interventions. Wiley, 2011.

26 Moher D, Liberati A, Tetzlaff J, et al. Preferred reporting items for systematic reviews and meta-analyses: the PRISMA statement. BMJ 2009;339.

27 Jawad M, Jawad S, Waziry RK, et al. Interventions for waterpipe tobacco smoking prevention and cessation: a systematic review. Sci Rep 2016;6:25872.

28 Mostafa A, Mohammed HT, Hussein WM, et al. Would placing pictorial health warnings on waterpipe devices reduce waterpipe tobacco smoking? A qualitative exploration of Egyptian waterpipe smokers' and non-smokers' responses. Tob Control 2019;28:475-8.

29 McKelvey K, Attonito J, Madhivanan P, et al. Determinants of cigarette smoking initiation in Jordanian schoolchildren: Iongitudinal analysis. Nicotine Tob Res 2015;17:552-8.

30 Hyland A, Ambrose BK, Conway KP, et al. Design and methods of the population assessment of tobacco and health (path) study. Tob Control 2017;26:371-8. 